\title{
Connecting Emotion Regulation to Career Outcomes: Do Proactivity and Job Search Self-Efficacy Mediate This Link?
}

This article was published in the following Dove Press journal:

Psychology Research and Behavior Management

\author{
Itziar Urquijo (D) \\ Natalio Extremera (iD ${ }^{2}$ \\ Josu Solabarrieta (iD) ${ }^{3}$ \\ 'University of Deusto, Faculty of \\ Psychology and Education, Department \\ of Physical Activity and Sport Sciences, \\ Bilbao 48007, Spain; ${ }^{2}$ University of \\ Malaga, Faculty of Psychology, \\ Department of Social Psychology, Social \\ Work, Social Anthropology and East \\ Asian Studies, Málaga 2907I, Spain; \\ ${ }^{3}$ University of Deusto, Faculty of \\ Psychology and Education, Department \\ of Innovation and Educational \\ Organization, Bilbao 48007, Spain
}

Correspondence: Itziar Urquijo Email itziar.urkijo@deusto.es
Introduction: Over the last decade, emotion regulation has drawn much attention in the organisational literature, specifically in career outcomes. Although the relationship between emotion regulation and career outcomes has been well established, potential mechanisms that might account for this relationship are still unclear.

Method: This study attempts to narrow this gap by examining the mediating effect of proactivity and job search self-efficacy on the relationship between emotion regulation and career outcomes in a sample consisting of 399 graduates (277 women, 122 men) with ages ranging from 22 to 60 years $(\mathrm{M}=30.5, \mathrm{SD}=8.26)$.

Results: Structural equation modelling showed partial mediation effects of job search selfefficacy between emotion regulation and career outcomes. However, no mediating effect was found for proactivity.

Discussion: These results suggest that the promotion of emotion regulation and self-efficacy may be fundamental in the development of programmes for career outcomes. Finally, implications and limitations of the present findings are discussed.

Keywords: emotion regulation, career outcomes, proactivity, job search, self-efficacy, graduates

\section{Introduction}

In recent decades, there has been an increasing enthusiasm from practitioners and academics on the role of emotions in different domains of organisational outcomes. In particular, recent studies have underlined emotion regulation as a protective factor that reduces adverse reaction to stress in the workplace. ${ }^{1,2}$ In addition, a literature review has documented that people with a high ability to recognise and understand their own and others' emotions typically report higher positive attitudes and job performance in organisational settings. ${ }^{3,4}$ On the other hand, those employees with high levels of emotion regulation are able to cope more effectively with negative job stressors compared to their less emotionally skilful counterparts. ${ }^{5,6}$ In turn, managing emotions appropriately is associated with positive job attitudes, including higher job satisfaction and less burnout. ${ }^{7-9}$ Finally, several studies have suggested that high levels of emotional intelligence significantly decrease employees' quit intentions because of their ability to better regulate emotions. ${ }^{10-12}$

Understanding of employees' emotional perspectives in the workplace, far less is known about the implications of the job search process and the resulting job outcomes. Keeping in mind that initial job search is a dynamic process full of uncertainty where job 
seekers became discouraged further studies examining the potential underlying mechanism linked during the job search process are needed. ${ }^{13}$ Understanding the contextual and personal resources that influence the job search process may help job search counsellors to identify potential risks related to adverse reaction to job process search, and ultimately negative career outcomes. ${ }^{14}$ Due to the perception of a lack of job search progress, job seekers typically become discouraged and decrease their job-search persistence and intentions. ${ }^{15}$ In particular, the need for increasing our understanding of the predictors, processes, and consequences of job search behaviour using integrative perspectives is needed, specifically in the Spanish population where the unemployment rate is $14.9 \%$, exceeding that of most countries in the European Union. ${ }^{16}$ This positions Spain in a critical situation because evidence shows that there is an increasing pessimism about welfare states and a frustration related to employment that is predominant among citizens. $^{17,18}$

According to this view, it is important to consider individual differences involved in the job search process and consequent career outcomes to find potential mechanisms in the prediction of career success. On the one hand, emotional abilities have emerged as a personal protective factor, which allows employees to reframe job search adversity and threatening events often associated with psychological maladjustment, thereby overcoming more efficiently employment difficulties. ${ }^{19}$ On the other hand, some specific personal variables related to job search process, such as perseverance and self-confidence, should be taken into account. According to meta-analytic research, ${ }^{20}$ these variables have been proved to be crucial for the job search process.

Thus, the analysis of personal resources as emotionregulation strategies and their interplay with job-search self-efficacy, proactivity and career outcomes should be examined in depth as a way to help job seekers to have a more balanced job search experience and avoid negative health consequences. $^{21,22}$

\section{Emotion Regulation and Career Outcomes}

Emotion regulation is one of the key dimensions repeatedly found as predictor that may contribute to adaptive positive career progress. $^{23,24}$ Likewise, emotion-regulation abilities may also be associated with positive career outcomes, given the importance of management of one's own and others' emotions, through an emotionally challenging and stressful job-seeking process. These regulatory abilities are essential for working effectively in workplaces characterised by ambiguity, fast-paced innovation, new competitive threats and opportunities and unpredictable changing roles. ${ }^{25}$ For most generally accepted theoretical approaches, emotion regulation is considered a major component of emotional intelligence, as it directly affects emotional expression and behaviour in different settings. ${ }^{26,27}$ Among the core emotional intelligence abilities proposed by Mayer and Salovey, ${ }^{28}$ the ability to manage emotions is expected to be most strongly associated with personal and workplace outcomes in accordance with previous findings with relevant workplace criteria. ${ }^{22}$ However, there is considerable debate in the definition and components of emotion regulation; sometimes this results in the lack of a consensual definition. ${ }^{25}$ Within the framework of emotional intelligence, emotion regulation has been conceptualised as the capacity to regulate and manage emotional states in oneself to clarify the best options for what to do next. ${ }^{29}$ It suggests being conscious of the most effective strategies for modifying that emotion if desired. ${ }^{30}$

In relation to organisational aspects, emotion regulation seems to be one of the key relevant predictors of different career outcomes. ${ }^{31,32}$ A literature review suggests that career outcomes is a multidimensional construct that includes objective characteristics such as employment status, payment, and hierarchical level (i.e., from base-level worker to top managers). ${ }^{33}$ Regarding employment status, preliminary research suggests that the ability to regulate emotions contributes to people's capacity to achieve the goal of finding a job. ${ }^{34,35}$ Consequently, it has been shown that people with high levels of emotional regulation tend to use more career development strategies, which facilitate the job search process and subsequent employability. ${ }^{36}$ Thus, emotion regulation has become one of the best resources for reemployment and employability success because is an adequate performance facilitator that might be helpful in job search situations. ${ }^{37-39}$

Salary is another indicator or outcome career, which acts as a reward to motivate employees. ${ }^{40}$ Concerning salary, predictors such as a good professional network or effectiveness under the influence of leaders have been related to emotion regulation. ${ }^{41}$ Moreover, those individuals who are able to maintain a positive mood in negative situations achieve higher salary levels. ${ }^{42}$ In line with previous research, recent studies have demonstrated the influence of emotion regulation in earning a higher salary, which becomes a key factor in the final stage of enhancing job performance. ${ }^{43}$ 
Even when employment status or salary adjust properly to employees requests, the concern about job insecurity remains. Therefore, the feeling of insecurity about job tenure acquires relevance when the constant organizational changes and the lack of stable job grow constantly. ${ }^{44}$ These contractual features are reflected in the stress produced by temporary contracts, which prevents life-long career. ${ }^{20,45,46}$ In other words, desirable long-term contracts are relevant, but when they cannot be achieved negative behavioural and emotional reactions appear. Thus, the ability to regulate emotions becomes critical to adjust negative reactions facing job security. ${ }^{47,48}$

Because of important positive implications linked to organisational settings, modern employers consider that a worker's individual characteristics may offer a competitive advantage, contributing to the development of its human capital. ${ }^{49,50}$ Thus, it should be thought that a positive relationship between emotion regulation and career outcomes will be possible (Hypothesis 1). Even though, it seems particularly important that researchers expand the existing findings by including underlying mechanisms that mediate these effects.

\section{Emotion Regulation, Proactivity, Job Search Self-Efficacy and Career Outcomes}

One set of mechanisms potentially underlying the link between emotion regulation and career outcomes are those related to the job search process. The job search process is the determinant factor of getting an acceptable job and might be determined by search methods, selfefficacy beliefs, and job-search intentions. ${ }^{51}$ Furthermore, developing a clear understanding of underlying mechanisms implied in the relationship between emotion regulation and job search outcomes may offer insight into modifiable targets for guidance programme with university graduates searching for a job. ${ }^{52}$

In the search for relevant factors in the job search process, recent studies have pointed job search self-efficacy as one of the key variables in the promotion of adaptability during the job search process, and for gaining more job offers, among others. ${ }^{53}$ Therefore, this dimension might be a key characteristic to gain control over their behaviour and to become more productive in their employment search among job seekers. ${ }^{54}$ In this context, job search self-efficacy is defined as an individual's confidence to perform the behaviours required to obtain the desired employment outcomes, such as a new job. ${ }^{54-57}$ Thus, university graduates with high job search self-efficacy have shown more active job search behaviour and also predicted employment status four months after graduation. ${ }^{58}$ Moreover, people with high self-efficacy typically direct more effort at pursuing a goal, ${ }^{59}$ obtaining more positive employment outcomes. ${ }^{60}$ In sum, the confidence people hold in their own capacity is a crucial factor to explain employment status. ${ }^{61}$ In addition, if we take into account that those individuals skilled in emotion regulation perceive themselves as more capable to engage in job search process and to show positive coping strategies, job search self-efficacy becomes crucial in the aforementioned relationship. ${ }^{62}$ Therefore, it will be expected that job search self-efficacy partially mediates the relationship between emotion regulation and career outcomes (Hypothesis 2).

Once the individuals are feeling confident about their own capacity, it is important to go a step further and act. Therefore, proactivity, which is defined as a stable disposition of taking a personal initiative in diverse situations, might be also relevant for adaptive and positive career outcomes among job seeker. ${ }^{63}$ It is known that the job search process depends on individuals' autonomy level, and what is more, it is a self-directed procedure that is limited by personal decisions. ${ }^{64}$ Hence, empirical findings suggest that people who are highly proactive show more initiative, ${ }^{60,65,66}$ identify opportunities ${ }^{35}$ and experience higher intrinsic motivation ${ }^{67}$ when they are engaged in the job search process. In sum, proactive people are more willing to cope with different adverse work environment aspects and persevere despite the stress of workplace challenging circumstances. ${ }^{68}$ Furthermore, some research have shown pieces of evidence about the capacity to use emotions to guide properly behaviour and thinking lead to individuals to take initiative. ${ }^{69}$ Thus, the examination of the interplay between the mentioned variables might help to analyse an underlying structured pattern of individual differences related to positive career outcomes. In sum, it could be assumed that proactivity will partially mediate the relationship between emotion regulation and career outcomes (Hypothesis 3).

Despite the connection between proactivity and job searching, self-efficacy has been consistently related in previous studies, ${ }^{62}$ but the underlying link with emotion regulation has scarcely been investigated. ${ }^{70,71}$ The limited research regarding the impact of emotional intelligence on proactivity ${ }^{11,72}$ shows that individuals with higher levels of emotional skills are more tolerant of stress and are characterised by positive affectivity, which, in fact, may impact proactivity. 


\section{Overview of the Current Study}

Overall, while the relationship between emotion regulation and career outcomes has been analysed, some fundamental aspects are still unclear. First, most of these studies have been focused on university students and emerging adults, leaving aside mid- or later-career adults. Besides, it has been shown that emotional responses have a stronger effect once the first two years of career have passed. ${ }^{5}$ Second, even if some studies have found a positive association between emotion regulation and general selfefficacy, ${ }^{73}$ it is necessary to gain a better understanding of how it affects specific job search self-efficacy. This is important to consider because it seems reasonable that emotion-regulation mechanisms of job seekers might affect task effort, persistence, and intensity within the multiple criteria of job search success. ${ }^{74}$ Finally, as emotion regulation might considerably influence the development of positive job attitudes and, as a result, improve career outcomes, it is important to extend the knowledge about underlying psychological mechanisms in this relationship. However, while conceptually intriguing, to date, no empirical studies have examined potential underlying mechanisms such as proactivity or job search self-efficacy, and most of the research has instead focused on examining the direct effect of emotion regulation on organisational outcomes.

The aim of this study, then, is to analyse the mediating effect of proactivity and job search self-efficacy on the relationship between emotion regulation and career outcomes (see Figure 1). In sum, it is expected to analyse causal steps when independent variable (X) affects dependent variable $(\mathrm{Y})$ through underlying relevant variables (M) in order to determine how the mediator fully or partially explained the effect. ${ }^{75}$

The consideration of multiple mediation is due to the fact that mediators do affect one another ${ }^{76}$ in these cases, it is recommended that mediation to be assessed with multiple mediators simultaneously to accommodate all factors. ${ }^{77}$ This would provide an empirical framework for

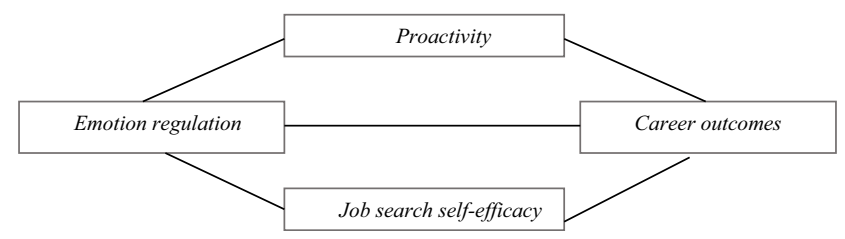

Figure I Hypothesized model of emotion regulation, career outcomes, proactivity and job search self-efficacy. researchers in the occupational environment, because, to our knowledge, no published studies have attempted to objectively examine these issues.

\section{Method}

\section{Participants and Procedure}

The participant group consisted of 399 graduates (277 women, 122 men). Participants' mean age was 30.55 years $(\mathrm{SD}=8.26$ years, range $=22-60$ years $)$ and $77.7 \%$ were employed and $22.3 \%$ unemployed. They came from the social and legal sciences (14.5\%), health sciences (14.5\%), arts and humanities (21.6\%), engineering and architecture (33.1\%) and science (16.3\%) departments. Participants were alumni of a private university of the south of Spain. They were voluntarily recruited through an online platform which enabled inclusion of former students from this university. Participants were informed about the confidentiality of the data and informed consent was obtained. Furthermore, the study was reviewed and approved by an institutional review board before it began. In particular, it was approved by University of Deusto Research Ethics Committee with the following reference ETK-10/17-18. Participation was voluntary; further, subjects had the option of participating in different non-economic raffles, such as cinema tickets, as well as receiving feedback from study results.

As part of the recruitment process, subjects completed a multi-section online questionnaire (lasting $20 \mathrm{mins}$ ). In comparison to the traditional paper-and-pencil method, the online data collection method has not been extensively considered in the literature, even though this format is becoming increasingly relevant. ${ }^{78}$ Some critiques of the approach are based on methodological issues, such as questionnaires that are too lengthy, the manner in which contact with the participants is made or the means used to encourage participation in online data collection. ${ }^{79}$ Nevertheless, findings have shown that paper-and-pencil and Internet data collection methods are generally equivalent in efficacy; further, the latter enables the obtaining of a great variety of answers and allows a hidden population to become visible. ${ }^{80}$

\section{Measures}

\section{Emotion Regulation}

The subscale of emotion regulation from the Wong-Law Emotional Intelligence Scale, ${ }^{81}$ Spanish version was administered. This self-report measure is based on the definition of emotional intelligence proposed by Salovey and Mayer. ${ }^{82}$ A growing number of studies (e.g., Ref. 82) have shown this trait to be predictive of positive psychological 
and social functioning. The full-scale measures four selfperceived emotional intelligence abilities: self-emotion appraisal, others' emotion appraisal, use of emotion and regulation of emotion. The regulation of emotions subscale consists of four items such as "I am able to control my temper and handle difficulties rationally". Respondents rated themselves from 1 (strongly disagree) to 5 (strongly agree). The Spanish WLEIS has shown satisfactory and acceptable psychometric properties. ${ }^{82}$ In this study, Cronbach's alpha for the regulation scale was 0.86 .

\section{Proactivity}

To measure proactivity, the 10-item shortened version of Bateman and Crant's ${ }^{60}$ original scale for proactive behaviour ${ }^{49}$ was used. Respondents indicated on a 7-point scale $(1=$ strongly disagree to $7=$ strongly agree $)$ whether the statements were "accurate descriptions of yourself" (e.g., "I love to challenge the status quo"). The English version of the scale ${ }^{60}$ was translated into Spanish and back-translated into English with the collaboration of local English and Spanish experts. First, an English-Spanish bilingual speaker translated the scale from English to Spanish. Then, a native English speaker with high Spanish proficiency backtranslate those items. Once both translations were finished, they were compared and a final version was created. As the original scale, the present instrument has shown good reliability with values of Cronbach's alpha of 0.88 in line with the 0.86 of the English version. ${ }^{57}$

\section{Job Search Self-Efficacy}

A two-item measure of job search self-efficacy ${ }^{40}$ from an adapted version by Ellis and Taylor ${ }^{83}$ was used. A 5-point Likert scale was used to indicate agreement $(1=$ strongly disagree, $5=$ strongly agree). In the same way, as for proactivity on the above-mentioned scale, a backtranslation was conducted by local English and Spanish experts. In this study, Cronbach's alpha was 0.77 , in line with the reliability shown in the original scale $0.70 .{ }^{84}$

\section{Career Outcomes}

\section{Employment Status}

This factor was measured by asking participants if they were working or not when they completed the questionnaire.

\section{Salary}

Salary was measured, restricting it to the range presented in previous studies. ${ }^{85}$ The amount of money received monthly was divided into seven categories: (1) no salary, (2) less than $€ 600$, (3) between $€ 600$ and $€ 1000$, (4) between $€ 1000$ and $€ 1200$, (5) between $€ 1200$ and $€ 1500$, (6) between $€ 1500$ and $€ 1800$, (7) between $€ 1800$ and $€ 2000$ and (8) more than $€ 2000$.

\section{Labour Stability/Job Security}

This factor was measured by type of contract: none, temporary or unlimited.

\section{Analysis Strategy}

Structural equation modelling (SEM) was used to examine the hypothesised model via the statistical packages SPSS and AMOS. ${ }^{86}$ The analysis of the mediation effect was carried out by adopting the two-step procedure. ${ }^{87}$ First, the measurement model was tested to furnish the link between the observed indicator variables and the underlying construct they were designed to measure. ${ }^{88}$ Once the confirmatory measurement model was evaluated, the structural model was tested using the maximum likelihood method. The measurement section of the model consisted of: (a) a general factor model measuring job outcomes and (b) a three-factor model measuring employment status, salary, and contract. Thus, the following indices were used to evaluate the goodness of fit of the model: ${ }^{89}$ chi-square statistics; comparative fit index (CFI); root-mean-square error of approximation (RMSEA); standardised root-mean-square residual (SRMR) and goodness of fit index (GFI). To compare the models, Akaike information criterion ${ }^{90}$ and expected cross-validation index ${ }^{91}$ were used. Previous work suggests that satisfactory model fit is indicated by CFI values above 0.95, RMSEA values of 0.06 or less, SRMR values no higher than 0.08 , and a chi-square goodness of fit to degrees of freedom ratio no greater than 2.,32 For the Akaike and ECVI comparison criteria, the smallest values were chosen, which show a greater potential for replication. Finally, a bootstrapping procedure was used, using 95\% confidence intervals and resampled 1000 times, which is thought to provide the most accurate confidence intervals for indirect effects. ${ }^{4,92}$

\section{Results}

Table 1 presents descriptive statistics as well as correlations between predictor and criterion variables. As can be seen, emotion regulation was positively and significantly related to all aspects of career outcomes, proactivity and job search self-efficacy. Thus, proactivity and job search self-efficacy were positively associated with them and with employment status, salary, and contract type. 
Table I Descriptive Statistics, and Zero-Order Correlations

\begin{tabular}{|c|c|c|c|c|c|c|c|c|}
\hline & Mean & SD & I & 2 & 3 & 4 & 5 & 6 \\
\hline I. Emotion regulation & 4.81 & 1.06 & & $0.222 * *$ & $0.187^{* *}$ & $0.165 * *$ & $0.297 * *$ & $0.179 * *$ \\
\hline 2. Employment status & 1.77 & 0.41 & & & $0.416^{* *}$ & $0.737 * *$ & $0.177 * *$ & $0.323 * *$ \\
\hline 3. Salary & 4.13 & 2.52 & & & & $0.472^{* *}$ & $0.150 * *$ & $0.150 * *$ \\
\hline 4. Contract type & 2.02 & 0.79 & & & & & $0.142 * *$ & $0.240 * *$ \\
\hline 5. Proactivity & 4.92 & 0.89 & & & & & & $0.190 * *$ \\
\hline 6. Job search self-efficacy & 2.71 & 1.13 & & & & & & \\
\hline
\end{tabular}

Notes: $\mathrm{N}=399 .{ }^{*} \mathrm{p}<0.01$.

\section{Measurement Model}

For purposes of comparison, the hypothesised single-factor model and another three-factor model were compared. In order to compare and select among the competing structural models, fit statistics were analysed (see Table 2). According to the AIC value, the single-factor model showed a smaller index, 331,718, compared to the three-factor model which showed a 413.815 index. Furthermore, a slightly smaller ECVI value suggested (single-factor model 0.833 and for three-factor model 1.040) that the fit of the single-factor model was more satisfactory and contributed find the most appropriate model. Moreover, the ratio $\mathrm{X}^{2} / \mathrm{df}$ for the threefactor model was 1.95 and for single-factor model, in turn, 1.14. In addition, following the principle of parsimony where the simplest equation modelling takes precedence, ${ }^{93}$ the single-factor model showed more potential for replication.

The measurement model included 4 latent factors (emotion regulation, career outcomes, proactivity and job search selfefficacy) and 19 observed variables. The model shown in Figure 2 revealed satisfactory fit for the data, $\mathrm{X}^{2}=115.718$ $(\mathrm{df}=101, p<0.001)$ being the ratio $\mathrm{X}^{2} / \mathrm{df}=1.14, \mathrm{CFI}=0.995$, RMSEA $=0.019$, TLI $=0.992$, SRMR $=0.080$, AIC $=$ 331,718. All the factor loadings for the indicators of the latent variable were significant, which means that all the latent factors were well represented by each indicator.

\section{Structural Model for Mediation Analysis}

The results of the proposed mediation analyses are shown in Table 3 and Figure 2. The direct path coefficient from the predictor (emotion regulation) to the criterion (career outcomes) in the absence of mediators was significant, $\beta=0.16, p<0.05$ (95\% percentile confidence interval $0.010-0.094)$. At the same time, the direct effect from emotion regulation to job search self-efficacy was $\beta=0.22, p<0.001$ (95\% percentile confidence interval $0.089-0.335$ ) and proactivity was still relevant with a direct path of $\beta=0.31, p<0.001$ ( $95 \%$ percentile confidence interval $0.213-547$ ). In short, the standardised total effect of emotion regulation on career outcomes was $\beta=0.25, p<0.01$ ( $95 \%$ percentile confidence interval: $0.027-0.120)$. Proactivity did not have a statistically significant direct effect on career outcomes, $\beta=0.06$ (95\% confidence interval $-0.004-0.054)$. However, job search selfefficacy had a statistically significant direct effect on career outcomes, $\beta=0.30, p<0.01$ (95\% percentile confidence interval $0.056-0.140$, ) along with indirect effects on career outcomes $\beta=0.08, p<0.05$ ( $95 \%$ percentile confidence interval $0.011-0.049)$. The proportion of variance in career outcomes explained by the collective set of predictors was $17 \%$.

Thus, as shown in Figure 2, emotion regulation exhibited a significant indirect effect on career outcomes via job search self-efficacy. However, no significant relationship was found when proactivity mediated the relationship between emotion regulation and career outcomes.

\section{Discussion}

Although prior work ${ }^{94}$ has suggested that emotion regulation might be a determinant of opportunities for gaining employment and obtaining better career outcomes, there is a lack of research examining the potential underlying mechanisms in this association. Thus, in the present study, we tried to

Table 2 Fit Indices Among Competing Models

\begin{tabular}{|l|l|l|l|l|l|l|l|}
\hline & $\mathbf{x}^{2}$ & $\mathbf{d f}$ & $\mathbf{R M S E A}$ & SRMR & CFI & AIC & ECVI \\
\hline Single factor model & 115.791 & 102 & 0.0346 & 0.080 & 0.996 & 329.791 & 0.829 \\
Three factor model & 199.549 & 102 & 0.049 & 0.051 & 0.969 & 413.815 & 1.04 \\
\hline
\end{tabular}

Abbreviations: RMSEA, root mean square error approximation; SRMR, standardized root mean square residual; CFI, comparative fit index; AIC, Akaike information criterion; ECVI, expected cross-validation index. 


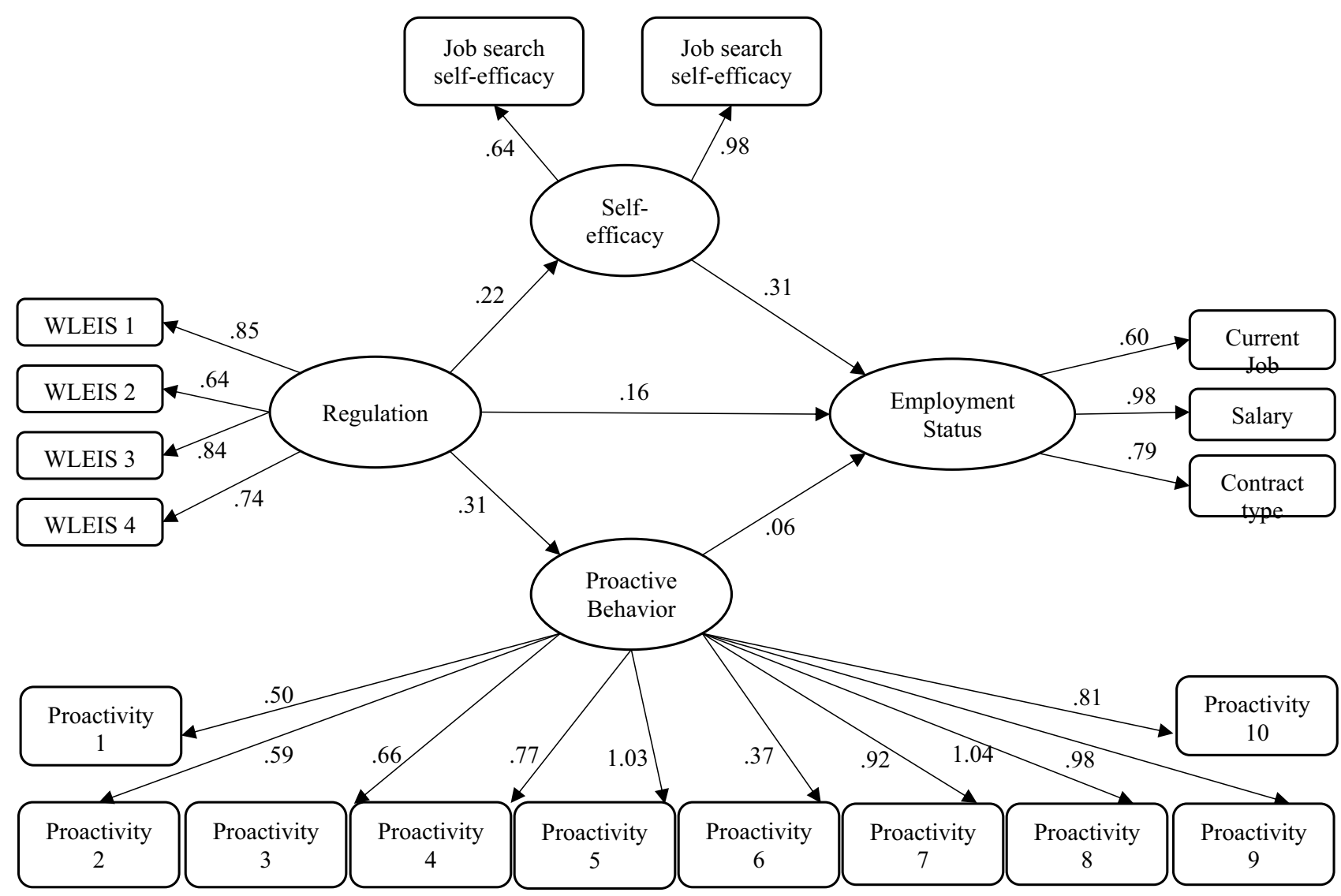

Figure 2 The finalized structural model $(\mathrm{N}=399)$.

Abbreviations: ER, emotion regulation, ERI-ER4, four parcels of emotion regulation; P, Proactivity, PI-PI0, ten parcels of proactivity; JSSE, job search self-efficacy, JSSEIJSSE2, two parcels of job search self-efficacy. Factor loadings are standardized.

integrate and expand the results from previous research by including the mediating effect of proactivity and job search self-efficacy in the link between emotion regulation and career outcomes.

Findings from the current study provide support for hypothesis 1, showing moderate correlations between emotion regulation and career outcomes in concordance with previous work. ${ }^{95}$ Theoretically, emotion regulation might shape emotional experience and behaviour which may be crucial when individuals are involved in a job search and must also cope with the demands of everyday life. ${ }^{96}$ Finding a job entails a recruitment process managed by different interviews or situations where the job seekers deal with conflict resolution. ${ }^{97}$ In these circumstances, people with a high capacity to elicit unpleasant emotions and adapt to different scenes tend to receive better interview feedback and outcomes. ${ }^{98}$ In addition, those individuals who show high emotion-regulation ability are able to induce a positive effect in others, ${ }^{29,99,100}$ which can be useful in relationships with interviewers or human resources. In sum, those employees who think that they can control their emotions effectively will perceive

Table 3 Standardized Direct and Indirect Effects and the Associated 95\% Confidence Intervals

\begin{tabular}{|l|l|l|l|l|l|l|}
\hline \multicolumn{2}{|l|}{} & \multicolumn{2}{l|}{ Proactivity } & \multicolumn{2}{l|}{ Job Search Self-Efficacy } & \multicolumn{2}{l|}{ Career Outcomes } \\
\hline & Direct & Indirect & Direct & Indirect & Direct & Indirect \\
\hline $\begin{array}{l}\text { Emotion regulation } \\
\text { Proactivity } \\
\text { Job search self-efficacy }\end{array}$ & $0.31^{* *}[0.217-0.552]$ & & $0.22^{* * *}[0.086-0.335]$ & & $0.14^{*}[0.014-0.084]$ & $0.1 I^{*}[0.044-0.173]$ \\
& & & & $0.09[-0.004-0.047]$ & $0.32^{* *}[0.064-0.136]$ & \\
\hline
\end{tabular}

Notes: The upper and lower bounds shown in parentheses were based on the findings from a bootstrapping. ${ }^{*} p<0.05$, $* * p<0.01, * * * p<0.001$ 
themselves as more employable, facilitating their job search process and subsequent job outcomes. ${ }^{99}$

Once the job is obtained, having job security becomes relevant because it has been shown that those employees with temporary contracts feel themselves with less quality of working life than those with permanent contracts. ${ }^{58,101}$ In this line, it is recognised that people with a high ability of emotion regulation are capable of making predictions about consequences and modifying responses to a situation in order to maintain a balanced organisational position. ${ }^{35}$ In addition, individuals who are able to facilitate interpersonal relationships in the workplace receive better supervisor remarks and as a result, obtain better merit pay. ${ }^{102}$

Regarding mediational approach, we found that job search self-efficacy mediates the relationship between emotion regulation and career outcomes in line with hypothesis 2. One plausible reason for the mediation is that emotion regulation might influence how intensively and successfully people look for employment, thus affecting their judgements, perceived self-efficacy, decisions and reactions in the job search process. ${ }^{62,68,82}$ Furthermore, it has been shown that employees who are able to overcome difficulties during the job search and in the workplace feel more prepared to progress in their employment, improving their chances of success. ${ }^{69}$ Thus, becoming confident about engaging in the job search process helps to support a more intense job search and increases the possibility of reaching better career outcomes. This may be related to the fact that individuals who assume higher self-efficacy beliefs tend to get a job sooner than those with lower conviction do. ${ }^{68}$

On the other hand, hypothesis 3 was not supported because, even if a direct effect between emotion regulation and proactivity appeared, no mediational effect was found. These results suggest that those individuals who are able to manage their emotions properly take initiative in diverse uncertain situations. ${ }^{103}$ In turn, having more emotion regulation entail a more successful engagement in coping with work environment issues. ${ }^{104}$ However, the fact of not finding significant mediational effects does not coincide with previous studies where proactivity was linked to perseverance, initiative and attempts to shape environment. ${ }^{105}$ One plausible reason might be the stronger predictive capacity of proactivity for subjective occupational outcomes than for objective aspects like employment status, contract type or salary. ${ }^{106}$ Another explanation might be related to the existing closeness between professional proactivity and calling. Somehow, people that showed a strong proactivity during job search process could present career inflexibility and limit their employability options. ${ }^{107}$ Accordingly, further research should include other underlying abilities involved in the job search process to examine a more integrative model of career outcomes. Some limitations of the present study should be noted. First, due to the operational definition of emotion regulation, the present study has used a theoretical approach of emotion regulation characterised by considering emotion regulation as a general perceived ability. However, other theoretical frameworks about emotion regulation conceptualized as a process are also relevant and may be considered for future research, examining its role both before and after emotional responses occur. ${ }^{108}$ Further, this research relied on self-reported measures, which may be susceptible to several biases, including social desirability. There may be differences based on a shared variance method using multiple methods of performance approaches. Also, our results have relied on some instruments for the measurement of job search self-efficacy and proactivity not previously validated in Spanish population, which might limit the generalization of our findings. Future research with well-validated Spanish tools for measuring these constructs is needed to confirm the usefulness and validity of our findings.

Moreover, this study was based on a convenience sample with graduates from a wide variety of educational areas and jobs, but they came from the same university. Thus, our study included a largely female graduate sample, which may not necessarily generalise to normative populations. In addition, an online method was used, which may reduce the response control. Hence, future studies should address these issues using multimethod approaches and replicating other educational groups in different samples. Importantly, our study design was cross-sectional, which means that it is difficult to draw cause-effect inferences. Thus, future research should examine our proposed mediational model using longitudinal and experimental methods. Finally, it is important in further research to consider other variables that affect the job search process as important predictors of career outcomes. For instance, recent research has suggested that reemployment crafting might be a key variable to shape job performance. ${ }^{109}$ In addition, given their adverse effects for the job search process itself, some economic dimensions such as levels of financial strain might be considered. ${ }^{110}$ Finally, job search process is influenced by multiple personal resources, one of them might be psychological capital (Chen \& Lim, 2012). Therefore, it would be important in 
further studies with job seekers to determine if there are potential interaction between this personal resource (i.e. psychological capital) and emotion regulation in the prediction of job search outcomes. ${ }^{94,111}$

Despite these limitations, this study is one of the first attempts to examine the underlying mechanism between emotional regulation and career outcomes in university graduates. To the extent that job search process and workplace are characterized by competition, fast-paced innovation, and unpredictable and stressful settings, fostering emotion regulation abilities might be a key factor in this process. ${ }^{110}$ Moreover, emotion regulation is required when employees are dealing with challenges such as job insecurity or unemployment situations, because it may lead to more effective strategies to fully develop their potential. ${ }^{112}$ In addition, it is important to consider the reinforcement of job search self-efficacy due to the fact that it leads to persistent attitudes and it is related to different job search intentions and behaviour. ${ }^{113}$ Thus, job search counsellors should focus on job search instruction and preparation and assist job seekers in becoming confident about finding new jobs. $^{114}$

In conclusion, our study suggests the need for job network services and career counsellors to complement existing job search intervention programmes. Even though some ground-breaking programmes have promoted job club to increase self-efficacy ${ }^{56}$ or the training of emotion-regulation skills and emotional self-efficacy to foster employability, ${ }^{115}$ these programmes have been typically performed separately. Thus, considering that recent studies have reinforced the importance of developing emotion-regulation intervention programmes, ${ }^{116}$ the inclusion of job search self-efficacy intervention might improve potential positive benefits. Accordingly, it would be interesting to include some activities such as role-playing, reflexive activities, readings or group activities based on a rigorous theoretical model. ${ }^{13}$ This might be particularly important for young adults entering the workplace for the first time and for those who are in the process of initial stages of reemployment. ${ }^{19}$ Keeping in mind all mentioned earlier, it calls for developing more integrative models of job search success that take into consideration the interplay of these personal resources to improve the job-seeking process.

\section{Disclosure}

The authors report no conflicts of interest in this work.

\section{References}

1. Grandey AA. Emotional regulation in the workplace: a new way to conceptualize emotional labor. J Occup Health Psychol. 2000;5 (1):95-110. doi:10.1037/1076-8998.5.1.95

2. Troth AC, Lawrence SA, Jordan PJ, Ashkanasy NM. Interpersonal emotion regulation in the workplace: a conceptual and operational review and future research agenda. Int J Manag Rev. 2017;20 (2):523-543. doi:10.1111/ijmr.12144

3. Cotê S, Hideg I. The ability to influence others via emotion displays: a new dimension of emotional intelligence. Organ Psychol Rev. 2011;1(1):53-71. doi:10.1177/2041386610379257

4. Côté S, Miners CTH, Moon S. Emotional intelligence and wise emotion regulation in the workplace. In: Zerbe WJ, Ashkanasy NM, Härtel CEJ, editors. Individual and Organizational Perspectives on Emotion Management and Display. Bingley: Emerald Group Publishing Limited; 2006:1-24. doi:10.1016/S1746-9791(06)02001-3

5. Blanco-Donoso LM, Garrosa E, Demerouti E, Moreno-Jiménez B. Job resources and recovery experiences to face difficulties in emotion regulation at work: a diary study among nurses. Int $J$ Stress Manag. 2017;24(2):107-134. doi:10.1037/str0000023

6. Huang H, Liu L, Yang S, Cui X, Zhang J, Wu H. Effects of job conditions, occupational stress, and emotional intelligence on chronic fatigue among Chinese nurses: a cross-sectional study. Psychol Res Behav Manag. 2019;12:351-360. doi:10.2147/ PRBM.S207283

7. Mérida-López S, Extremera N, Rey L. Emotion-regulation ability, role stress and teachers' mental health. Occup Med (Chic Ill). 2017;67(7):540-545. doi:10.1093/occmed/kqx125

8. Miao C, Humphrey RH, Qian S. A meta-analysis of emotional intelligence and work attitudes. J Occup Organ Psychol. 2017;90 (2):177-202. doi:10.1111/joop.12167

9. Brackett MA, Palomera R, Mojsa-Kaja J, Reyes MR, Salovey P. Emotion-regulation ability, burnout, and job satisfaction among British secondary-school teachers. Psychol Sch. 2010;47 (4):406-417. doi:10.1002/pits. 20478

10. Ahmad SA, Seleim A, Bontis N, Mostapha N. Emotional intelligence and career outcomes: evidence from lebanese banks. Knowl Process Manage. 2017;24(3):161-169. doi:10.1002/kpm.1533

11. Chi S-CS, Liang S-G. When do subordinates' emotion-regulation strategies matter? Abusive supervision, subordinates' emotional exhaustion, and work withdrawal. Leadersh Q. 2013;24 (1):125-137. doi:10.1016/j.leaqua.2012.08.006

12. Côté S, Morgan LM. A longitudinal analysis of the association between emotion regulation, job satisfaction, and intentions to quit. J Organ Behav. 2002;23(8):947-962. doi:10.1002/job.174

13. Wanberg CR, Glomb TM, Song Z, Sorenson S. Job-search persistence during unemployment: a 10-wave longitudinal study. J Appl Psychol. 2005;90(3):411-430. doi:10.1037/0021-9010.90.3.411

14. Borgen W, Amundson NE. The dynamics of unemployment. $J$ Couns Dev. 1987;66(4):180-184. doi:10.1002/j.1556-6676.1987.tb00841.x

15. Eurostat. Eurostat unemployment database. 2019. 2018. Available from: https://ec.europa.eu/eurostat/statistics-explained/index.php? title=Employment_statistics/es. Accessed June 9, 2019.

16. Alonso LE, Fernández Rodríguez $\mathrm{C}$, Ibáñez Rojo R. Entre la austeridad y el malestar: discursos sobre consumo y crisis económica en España. Reis Rev Esp Investig Sociol. 2016;155:21-36. doi:10.5477/cis/reis.155.21

17. Kreemers LM, Van Hooft EAJ, Van Vianen AEM. Dealing with negative job search experiences: the beneficial role of selfcompassion for job seekers' affective responses. $J$ Vocat Behav. 2018;106:165-179. doi:10.1016/j.jvb.2018.02.001

18. Van Hal G. The true cost of the economic crisis on psychological well-being: a review. Psychol Res Behav Manag. 2015;8:17-25. doi:10.2147/PRBM.S44732 
19. Angeles Peláez-Fernández M, Rey L, Extremera N. Psychological distress among the unemployed: do core self-evaluations and emotional intelligence help to minimize the psychological costs of unemployment? J Affect Disord. 2019;256:627-632. doi:10.1016/ j.jad.2019.06.042

20. Kanfer R, Wanberg CR, Kantrowitz TM. Job search and employment: a personality-motivational analysis and meta-analytic review. J Appl Psychol. 2001;86(5):837-855. doi:10.1037//0021-9010. 86.5.837

21. Petrides KV. Trait emotional intelligence theory. Ind Organ Psychol. 2010;3(2):136-139. doi:10.1111/j.1754-9434.2010.01213.x

22. Salovey P, Mayer JD. Emotional intelligence. Imagin Cogn Pers. 1990;9(3):185-211. doi:10.2190/DUGG-P24E-52WK-6CDG

23. Römgens I, Scoupe R, Beausaert S. Unraveling the concept of employability, bringing together research on employability in higher education and the workplace. Stud High Educ. 2019;1-16. doi: 10.1080/03075079.2019.1623770

24. Prakash Mulki J, Jaramillo F, Goad EA, Rivera Pesquera M. Regulation of emotions, interpersonal conflict, and job performance for salespeople. J Bus Res. 2014;68:623-630. doi:10.1016/j. jbusres.2014.08.009

25. Mayer JD, Salovey P. What is emotional intelligence. In: Salovey P, Sluyter D, editors. Emotional Development and Emotional Intelligence: Implications for Educators. New York: Basic Books; 1997:3-31.

26. Côté S. emotional intelligence in organizations. Annu Rev Organ Psychol Organ Behav. 2014;1(1):459-488. doi:10.1146/annurevorgpsych-031413-091233

27. Mayer JD, Salovey P. Emotional intelligence and the construction and regulation of feelings. Appl Prev Psychol. 1995;4::197-208. doi:10.1016/S0962-1849(05)80058-7

28. Gross JJ. Handbook of Emotion Regulation. New York: The Guilford Press; 2014.

29. Côtè S. A social interaction model of the effects of emotion regulation on work strain. Acad Manag Rev. 2005;30(3):509-530. doi:10.5465/amr.2005.17293692

30. Diefendorff JM, Richard EM, Yang J. Linking emotion regulation strategies to affective events and negative emotions at work. $J$ Vocat Behav. 2008;73(3):498-508. doi:10.1016/J.JVB.2008.09.006

31. González-Romá V, Gamboa JP, Peiró JM. University graduates' employability, employment status, and job quality. J Career Dev. 2018;45(2):132-149. doi:10.1177/0894845316671607

32. Creed PA, King V, Hood M, McKenzie R. Goal orientation, self-regulation strategies, and job-seeking intensity in unemployed adults. J Appl Psychol. 2009;94(3):806-813. doi:10.1037/a0015518

33. Praskova A, Creed PA, Hood M. Self-regulatory processes mediating between career calling and perceived employability and life satisfaction in emerging adults. J Career Dev. 2015;42(2):86-101. doi: $10.1177 / 0894845314541517$

34. Brief AP, Weiss HM. Organizational behavior: affect in the workplace. Аnnu Rev Psychol. 2002;53(1):279-307. doi:10.1146/annurev. psych.53.100901.135156

35. Hodzic S, Ripoll P, Lira E, Zenasni F. Can intervention in emotional competences increase employability prospects of unemployed adults? $J$. Vocat.Behav. 2015;88:28-37. doi:10.1016/j.jvb.2015.02.007

36. Prakash Sharma J, Bajpai N. Salary satisfaction as an antecedent of job satisfaction: development of a regression model to determine the linearity between salary satisfaction and job satisfaction in a public and a private organization. Eur.J.Soc.Sci. 2011;18(3):450-461.

37. Rode JC, Arthaud-Day M, Ramaswami A, Howes S. A time-lagged study of emotional intelligence and salary. $J$ Vocat Behav. 2017;101:77-89. doi:10.1016/j.jvb.2017.05.001

38. Lopes PN, Grewal D, Kadis J, Gall M, Salovey P. Evidence that emotional intelligence is related to job performance and affect and attitudes at work. Psicothema. 2006;18:Suppl:132-138: 132-138.
39. Sjöberg L. Emotional intelligence and life adjustment. In: Cassady J, Eissa M, editors. Emotional Intelligence. Perspectives on Educational \& Positive Psychology. New York: Peter Lang Publishing; 2008:169-184.

40. De Haro J-M, Castejón J-L. Inteligencia emocional percibida, inteligencia general y éxito profesional en el inicio de la carrera: validez predictiva e incremental. An Psicol. 2014;30(2):490-498. doi:10.6018/analesps.30.2.154621

41. De Haro JM, Castejon JL, Gilar R. Personality and salary at early career: the mediating effect of emotional intelligence. Int $J$ Hum Resour Manage. 2018;1-19. doi:10.1080/09585192.2017.1423365

42. Luthans F, Youssef CM. Human, social, and now positive psychological capital management. Organ Dyn. 2004;33(2):143-160. doi:10.1016/j.orgdyn.2004.01.003

43. Shakir M, Zia A. Temporary job and permanent stress. J Educ Pract. 2014;5(14):144-150.

44. Jordan PJ, Ashkanasy NM, Hartel CEJ. Emotional intelligence as a moderator of emotional and behavioral reactions to job insecurity. Acad Manag Rev. 2002;27(3):361. doi:10.2307/4134384

45. Blau DM, Robins PK. Job search outcomes for the employed and unemployed. J Polit Econ. 1990;98(31):637-655. doi:10.1086/ 261698

46. Piróg D. Job search strategies of recent university graduates in Poland: plans and effectiveness. High Educ. 2016;71(4):557-573. doi:10.1007/s10734-015-9923-5

47. Wanberg CR, Zhu J, Hooft EV. The job search grind: perceived progress, self-reactions, and self-regulation of search effort. Acad Manag J. 2010;53:788-807. doi:10.2307/20788792

48. Wanberg CR, Watt J, Rumsey DJ. Individuals without jobs: an empirical study of job-seeking behavior and reemployment. J Appl Psychol. 1996;81(1):76-87. doi:10.1037/0021-9010.81.1.76

49. Ellis RA, Taylor MS. Role of self-esteem within the job search process. J Appl Psychol. 1983;68(4):632-640. doi:10.1037/00219010.68.4.632

50. Nesdale D, Pinter K. Self-efficacy and job-seeking activities in unemployed ethnic youth. J Soc Psychol. 2000;140(5):608-614. doi:10.1080/00224540009600500

51. Saks AM, Ashforth BE. Effects of individual differences and job search behaviors on the employment status of recent university graduates. J Vocat Behav. 1999;54(2):335-349. doi:10.1006/jvbe.1998.1665

52. Bandura A. Self-Efficacy : The Exercise of Control. New York: Worth Publishers; 1997.

53. Kim JG, Kim HJ, Lee K-H. Understanding behavioral job search self-efficacy through the social cognitive lens: a meta-analytic review. J Vocat Behav. 2019;112:17-34. doi:10.1016/j.jvb.2019.01.004

54. Moynihan LM, Roehling MV, LePine MA, Boswell WR. A longitudinal study of the relationships among job search self-efficacy, job interviews, and employment outcomes. $J$ Bus Psychol. 2003;18(2):207-233. doi:10.1023/A:1027349115277

55. Guan Y, Deng H, Sun J, et al. Career adaptability, job search self-efficacy and outcomes: a three-wave investigation among Chinese university graduates. $J$ Vocat Behav. 2013;83(3):561-570. doi:10.1016/J.JVB.2013.09.003

56. Liu S, Huang JL, Wang M. Effectiveness of job search interventions: a meta-analytic review. Psychol Bull. 2014;140(4):1009-1041. doi: $10.1037 / \mathrm{a} 0035923$

57. Liu S, Wang M, Liao H, Shi J. Self-regulation during job search: the opposing effects of employment self-efficacy and job search behavior self-efficacy. J Appl Psychol. 2014;99(6):1159-1172. doi:10.1037/a0036692

58. Stajkovic AD, Luthans F. Self-efficacy and work-related performance: a meta-analysis. Psychol Bull. 1998;124(2):240-261. doi:10.1037/0033-2909.124.2.240 
59. Seibert S, Kraimer M, Crant M. What do proactive people do? A longitudinal model linking proactive personality and career success. Pers Psychol. 2001;54(4):845-874. doi:10.1111/j.1744-6570.2001. tb00234.x

60. Brown DJ, Cober RT, Kane K, Levy PE, Shalhoop J. Proactive personality and the successful job search: a field investigation with college graduates. J Appl Psychol. 2006;91(3):717-726. doi:10.1037/00219010.91.3.717

61. Becherer RC, Maurer G. The proactive personality disposition and entrepreneurial behavior among small company presidents. J Small Bus Manage. 1999;37(1):28-36.

62. Rode JC, Arthaud-Day ML, Mooney CH, Near JP, Baldwin TT. Ability and personality predictors of salary, perceived job success, and perceived career success in the initial career stage. Int J Sel Assess. 2008;16 (3):292-299. doi:10.1111/j.1468-2389.2008.00435.x

63. Crant JM. Proactive Behavior in Organizations. J Manage. 2000;26 (3):435-462. doi:10.1177/014920630002600304

64. Joo B-K, Lim T. The effects of organizational learning culture, perceived job complexity, and proactive personality on organizational commitment and intrinsic motivation. J Leadersh Organ Stud. 2009;16(1):48-60. doi:10.1177/1548051809334195

65. Zacher H, Bock A. Mature age job seekers: the role of proactivity. J Manag Psychol. 2014;29(8):1082-1097. doi:10.1108/JMP-052012-0158

66. Bao Z, Luo P. How college students' job search self-efficacy and clarity affect job search activities. Soc Behav Personal Int J. 2016;44(3):39-51. doi:10.2224/sbp.2015.43.1.39

67. Zampetakis LA, Kafetsios $\mathrm{K}$, Bouranta N, Dewett T, Moustakis VS. On the relationship between emotional intelligence and entrepreneurial attitudes and intentions. Int J Entrep Behav Res. 2009;15(6):595-618. doi:10.1108/13552550910995452

68. Kim T-Y, Cable DM, Kim S-P, Wang J. Emotional competence and work performance: the mediating effect of proactivity and the moderating effect of job autonomy. J Organ Behav. 2009;30 (7):983-1000. doi:10.1002/job.610

69. Jafri MH, Dem C, Choden S. Emotional intelligence and employee creativity: moderating role of proactive personality and organizational climate. Bus Perspect. 2016;4(1):54-66. doi:10.1177/ 2278533715605435

70. Durán A, Extremera N, Rey L, Fernández-Berrocal $\mathrm{P}$ Montalbán FM. Predicting academic burnout and engagement in educational settings: assessing the incremental validity of perceived emotional intelligence beyond perceived stress and general self-efficacy. Psicothema. 2006;18:Suppl:158-164.

71. Lee KH, Song JS. The effect of emotional intelligence on self-efficacy and job stress of nurses - mediating role of self-efficacy. $J$ Korean Acad Nurs Adm. 2010;16(1):17. doi:10.11111/jkana.2010.16.1.17

72. Stevens CK, Seo M-G. Job Search and Emotions. Cable DM, KYT Y, editors. Oxford: Oxford University Press; 2013.

73. Vanderweele T, Vansteelandt S. Mediation analysis with multiple mediators. Epidemiol Method. 2015;2(1):95-115. doi:10.1515/em2012-0010

74. Brickman Bhutta C. Not by the book. Sociol Methods Res. 2012;41 (1):57-88. doi:10.1177/0049124112440795

75. Lefever S, Dal M, Matthíasdóttir Á. Online data collection in academic research: advantages and limitations. $B r J$ Educ Technol. 2007;38 (4):574-582. doi:10.1111/j.1467-8535.2006.00638.x

76. Weigold A, Weigold IK, Russell EJ. Examination of the equivalence of self-report survey-based paper-and-pencil and internet data collection methods. Psychol Methods. 2013;18(1):53-70. doi:10.1037/a0031607

77. Wong C, Law KS. The effects of leader and follower emotional intelligence on performance and attitude : an exploratory study. Leadersh $Q$. 2002;13(3):243-274. doi:10.1016/S1048-9843(02)00099-1
78. Salovey P, Mayer J. Emotional intelligence. Imagin Cogn Pers 1990. doi:10.2190/DUGG-P24E-52WK-6CDG

79. Kafetsios K, Zampetakis LA. Emotional intelligence and job satisfaction: testing the mediatory role of positive and negative affect at work. Pers Individ Dif. 2008;44(3):712-722. doi:10.1016/j.paid.2007.10.004

80. Urquijo I, Extremera N, Villa A. Emotional intelligence, life satisfaction, and psychological well-being in graduates: the mediating effect of perceived stress. Appl Res Qual Life. 2016;11 (4):1241-1252. doi:10.1007/s11482-015-9432-9

81. Bateman TS, Crant JM. The proactive component of organizational behavior: A measure and correlates. J Organ Behav. 1993;14 (2):103-118. doi:10.1002/job.4030140202

82. Seibert SE, Crant JM, Kraimer ML. Proactive personality and career success. J Appl Psychol. 1999;84(3):416-427. doi:10.1037/ 0021-9010.84.3.416

83. Arbuckle J. Amos 4.0 User's Guide. Chicago: SmallWaters corporation; 1999.

84. Anderson JC, Gerbing DW. Structural equation modeling in practice: a review and recommended two-step approach. Psychol Bull. 1988;103(3):411-423. doi:10.1037/0033-2909.103.3.411

85. Byrne BM. Structural Equation Modeling with AMOS : Basic Concepts, Applications, and Programming. London: Routledge; 2010.

86. Hu L, Bentler PM. Cutoff criteria for fit indexes in covariance structure analysis: conventional criteria versus new alternatives. Struct Equ Model a Multidiscip J. 1999;6(1):1-55. doi:10.1080/ 10705519909540118

87. Akaike H. Factor analysis and AIC. Psychometrika. 1987;52 (3):317-332. doi:10.1007/BF02294359

88. Browne MW, Cudeck R. Alternative ways of assessing model fit. Sociol Methods Res. 1992;21(2):230-258. doi:10.1177/ 0049124192021002005

89. Bentler PM. Comparative fit indexes in structural models. Psychol Bull. 1990;107(2):238-246. doi:10.1037/0033-2909.107.2.238

90. Mackinnon DP, Lockwood CM, Williams J. Confidence limits for the indirect effect: distribution of the product and resampling methods. Multivariate Behav Res. 2004;39(1):99. doi:10.1207/ s15327906mbr3901_4

91. Carroll JB. How shall we study individual differences in cognitive abilities? Methodological and theoretical perspectives. Intelligence. 1978;2(2):87-115. doi:10.1016/0160-2896(78)90002-8

92. Joseph DL, Newman D. Emotional intelligence: an integrative meta-analysis and cascading model. J Appl Psychol. 2010;95 (1):54-78. doi:10.1037/a0017286

93. Tamir M, Rhodes E, Salerno J, Schreier J. An expectancy-value model of emotion regulation: implications for motivation, emotional experience, and decision making. Emotion. 2015;15 (1):90-103. doi:10.1037/emo0000021

94. Tay C, Ang S, Van Dyne L. Personality, biographical characteristics, and job interview success: a longitudinal study of the mediating effects of interviewing self-efficacy and the moderating effects of internal locus of causality. J Appl Psychol. 2006;91(2):446-454. doi:10.1037/0021-9010.91.2.446

95. Zeidner M, Matthews G, Roberts RD. Emotional intelligence in the workplace: a critical review. Appl Psychol. 2004;53(3):371-399. doi:10.1111/j.1464-0597.2004.00176.x

96. Carmeli A. The relationship between emotional intelligence and work attitudes, behavior and outcomes. J Manag Psychol. 2003;18 (8):788-813. doi:10.1108/02683940310511881

97. Dacre Pool L, Qualter P. Emotional self-efficacy, graduate employability, and career satisfaction: testing the associations. Aust J Psychol. 2013;65(4):214-223. doi:10.1111/ajpy.12023

98. Callea A, Urbini F, Ingusci E, Chirumbolo A. The relationship between contract type and job satisfaction in a mediated moderation model: the role of job insecurity and psychological contract violation. Econ Ind Democr. 2016;37(2):399-420. doi:10.1177/0143831X14546238 
99. Brackett MA, Rivers SE, Salovey P. Emotional intelligence: implications for personal, social, academic, and workplace success. Soc Personal Psychol Compass. 2011;5(1):88-103. doi:10.1111/j.17519004.2010.00334.x

100. Scott-Ladd B, Chan CCA. Emotional intelligence and participation in decision-making strategies for promoting organizational learning and change. Strateg Chang. 2004;13:95-105. doi:10.1002/jsc.668

101. Weng L-C, Huang H-L, Wang Y-W, Lee W-C, Chen K-H, Yang T-Y. The effect of self-efficacy, depression and symptom distress on employment status and leisure activities of liver transplant recipients. $J A d v$ Nurs. 2014;70(7):1573-1583. doi:10.1111/jan.12315

102. Pinquart M, Juang LP, Silbereisen RK. Self-efficacy and successful school-to-work transition: a longitudinal study. J Vocat Behav. 2003;63(3):329-346. doi:10.1016/S0001-8791(02)00031-3

103. Thomas JP, Whitman DS, Viswesvaran C. Employee proactivity in organizations: a comparative meta-analysis of emergent proactive constructs. J Occup Organ Psychol. 2010;83(2):275-300. doi:10.1348/096317910X502359

104. Lysova EI, Jansen PGW, Khapova SN, Plomp J, Tims M. Examining calling as a double-edged sword for employability. J Vocat Behav. 2018;104:261-272. doi:10.1016/J.JVB.2017.11.006

105. Gross JJ. Emotion regulation: current status and future prospects. Psychol Inq. 2015;26:1-26. doi:10.1080/1047840X.2014.940781

106. Carpenter SM, Yates JF, Preston SD, Chen L, Chopra S. Regulating emotions during difficult multiattribute decision making: the role of pre-decisional coherence shifting. Yechiam E, ed. PLoS One. 2016;11(3):e0150873. doi:10.1371/journal.pone.0150873

107. Hulshof IL, Demerouti E, Le Blanc PM. Reemployment crafting: proactively shaping one's job search. J Appl Psychol. 2019. doi:10.1037/ap10000419
108. Wanberg C, Dossinger K, Van Hooft E, Van Vianen A. How strong is my safety net? Perceived unemployment insurance generosity and implications for job search, mental health, and reemployment. J Appl Psychol. 2019;1-21. doi:10.1037/ap10000435

109. Georgiou K, Nikolaou I. The influence and development of psychological capital in the job search context. Int J Educ Vocat Guid. 2018;1-19. doi:10.1007/s10775-018-9385-2

110. Saks AM, Zikic J, Koen J. Job search self-efficacy: reconceptualizing the construct and its measurement. $J$ Vocat Behav. 2015;86:104-114. doi:10.1016/j.jvb.2014.11.007

111. Bandura A. Social Foundations of Though and Action: A Social Cognitive Theory. New Jersey: Prentice Hall; 1986.

112. Mattingly V, Kraiger K. Can emotional intelligence be trained? A meta-analytical investigation. Human Res Manage Rev. 2019;29 (2):140-155. doi:10.1016/J.HRMR.2018.03.002

113. Sterret E. Use of a job club to increase self-efficacy: a case study of return to work. J Employ Couns. 1998;35(2):69-78. doi:10.1002/ j.2161-1920.1998.tb00477.x

114. Dacre Pool L, Qualter P. Improving emotional intelligence and emotional self-efficacy through a teaching intervention for university students. Learn Individ Differ. 2012;22(3):306-312. doi:10.1016/j. lindif.2012.01.010

115. Gohm CL. Moving Forward with Emotional Intelligence. Psychol Inq. 2004;15(3):222-227. doi:10.2307/20447231

116. Gallie D, Felstead A, Green F, Inanc H. The hidden face of job insecurity. Work Employment Soc. 2017;31(1):36-53. doi:10.1177/ 0950017015624399
Psychology Research and Behavior Management

\section{Publish your work in this journal}

Psychology Research and Behavior Management is an international, peer-reviewed, open access journal focusing on the science of psychology and its application in behavior management to develop improved outcomes in the clinical, educational, sports and business arenas. Specific topics covered in the journal include: Neuroscience, memory and decision making; Behavior modification and management; Clinical

\section{Dovepress}

applications; Business and sports performance management; Social and developmental studies; Animal studies. The manuscript management system is completely online and includes a very quick and fair peer-review system, which is all easy to use. Visit http://www. dovepress.com/testimonials.php to read real quotes from published authors. 